(2) Open Access Full Text Article

\title{
Hepatocyte-targeting gene transfer mediated by galactosylated poly(ethylene glycol)- graft-polyethylenimine derivative
}

This article was published in the following Dove Press journal:

Drug Design, Development and Therapy

25 March 2013

Number of times this article has been viewed

\author{
Yuqiang Wang',* \\ Jing $\mathrm{Su}^{2}$,* \\ Wenwei Cai ${ }^{3}$ \\ Ping Lu ${ }^{3}$ \\ Lifen Yuan ${ }^{3}$ \\ Tuo Jin ${ }^{2}$ \\ Shuyan Chen' \\ Jing Sheng ${ }^{3}$
}

'Department of Geriatrics, Xinhua Hospital Affiliated to Shanghai Jiao

Tong University School of Medicine, Shanghai, People's Republic of China; ${ }^{2}$ School of Pharmacy, Shanghai Jiao Tong University, Shanghai, People's Republic of China; ${ }^{3}$ Department of Geriatrics, Shanghai Ninth People's Hospital Affiliated to Shanghai Jiao Tong University School of Medicine, Shanghai, People's Republic of China

*Both authors contributed equally to this work

Correspondence: Shuyan Chen Department of Geriatrics, Xinhua Hospital, Shanghai Jiao Tong University School of Medicine, 1665 Kongjiang Road, Shanghai 200092, People's Republic of China

Tel +86 I38 I680 2755

Email shuyanchencn@yahoo.com.cn

Jing Sheng

Department of Geriatrics, Shanghai Ninth People's Hospital, Shanghai Jiao

Tong University School of Medicine,

639 Zhizaoju Road, Shanghai 2000II,

People's Republic of China

Tel +86 I36 5I76 3।92

Email shengjing60@।63.com
Abstract: Biscarbamate cross-linked polyethylenimine derivative (PEI-Et) has been reported as a novel nonviral vector for efficient and safe gene transfer in our previous work. However, it had no cell-specificity. To achieve specific delivery of genes to hepatocytes, galactosylated poly(ethylene glycol)-graft-polyethylenimine derivative (GPE) was prepared through modification of PEI-Et with poly(ethylene glycol) and lactobionic acid, bearing a galactose group as a hepatocyte-targeting moiety. The composition of GPE was characterized by proton nuclear magnetic resonance. The weight-average molecular weight of GPE measured with a gel permeation chromatography instrument was $9489 \mathrm{Da}$, with a polydispersity of 1.44 . GPE could effectively condense plasmid DNA (pDNA) into nanoparticles. Gel retardation assay showed that GPE/pDNA complexes were completely formed at weigh ratios (w/w) over 3. The particle size of GPE/pDNA complexes was 79-100 nm and zeta potential was 6-15 mV, values which were appropriate for cellular uptake. The morphology of GPE/pDNA complexes under atomic force microscopy appeared spherical and uniform in size, with diameters of 53-65 nm. GPE displayed much higher transfection efficiency than commercially available PEI $25 \mathrm{kDa}$ in BRL-3A cell lines. Importantly, GPE showed good hepatocyte specificity. Also, the polymer exhibited significantly lower cytotoxicity compared to PEI $25 \mathrm{kDa}$ at the same concentration or weight ratio in BRL-3A cell lines. To sum up, our results indicated that GPE might carry great potential in safe and efficient hepatocyte-targeting gene delivery.

Keywords: gene delivery, hepatocyte targeting, galactose, cytotoxicity, transfection efficiency

\section{Introduction}

The curing effect of gene therapy greatly depends on safe and efficient delivery of therapeutic gene to the target site. ${ }^{1,2}$ In recent years, nonviral vectors have been investigated intensively for gene delivery, due to their ease of production and chemical modification, safety, lower immune response, and the capacity to delivery larger DNA molecules. ${ }^{3-5}$ Consequently, alternative gene carriers have been proposed based on nonviral vectors, such as cationic lipids ${ }^{6,7}$ and cationic polymers. ${ }^{8-13}$ However, there are still many obstacles that can hamper the delivery capability of nonviral carriers in vivo. ${ }^{14}$ For example, without modification with an appropriate targeting moiety, the carrier will have an increased risk of entering undesired cells and possibly cause damage to healthy tissues. Therefore, targeted transfer of nucleic acid drugs to specific tissues is a significantly important concern to address in the field of gene delivery.

Receptor-mediated endocytosis has been shown to be a promising way to achieve specific delivery of genes to certain cell types or tissues. Surface modification of 
nanosized vectors like nanoparticles is usually used for specific targeting purposes. Various ligands, including antibody, ${ }^{15}$ folate, ${ }^{16,17}$ asialoglycoprotein, ${ }^{18}$ galactose,${ }^{19,20}$ mannose, ${ }^{21}$ epidermal growth factor, ${ }^{22}$ and transferrin ${ }^{23}$ have been conjugated with nonviral carriers for cell specificity. It was reported that the asialoglycoprotein receptor (ASGPR) was abundantly expressed in normal hepatocytes and hepatoma cell lines, such as BRL-3A, HepG2, and parental human hepatocellular carcinoma BEL-7402 cells. There are on average 500,000 ASGPRs on every hepatocyte. ASGPR can selectively bind to galactose or $N$-acetylgalactosamine residues of desialylated glycoproteins. ${ }^{24}$ ASGPR has received much attraction in gene targeting and has also acted as a model system for studying receptor-mediated endocytosis due to its high affinity and rapid internalization rate. Therefore, the delivery of genes to hepatocytes through ASGPR-mediated endocytosis using galactosylated polymers has gained significant interest. For instance, as Gref et $\mathrm{al}^{25}$ reported, galactose-modified oligosaccharides displayed a high affinity for ASGPR in liver tumor cells. Gao et $\mathrm{al}^{26}$ reported a gene carrier based on galactosylated chitosans that showed obvious targeting in hepatoma cells HepG2, SMMC7721, and normal hepatic cell L-02. Kim et $\mathrm{al}^{27}$ conjugated galactose to poly(ethylene) glycol (PEG)-polyethylenimine (PEI) to obtain a hepatocyte-targeting gene carrier; the polymer they synthesized exhibited improved transfection efficiency in hepatoma cells.

In our previous work, we synthesized biscarbamate crosslinked PEI derivative (PEI-Et) as a nonviral gene carrier. Our results showed that PEI-Et displayed significantly enhanced transfection efficiency and much lower cytotoxicity than commercially available PEI $25 \mathrm{kDa}$ in three cell lines (COS7, BRL-3A, and HeLa). ${ }^{28}$ However, the polymer had no cellspecificity. Therefore, in the present study, galactosylated PEG-graft-PEI derivative (GPE) was prepared to achieve hepatocyte specificity. Two chemical modifiers, PEG and galactose, were included in GPE. Galactose was acted as a hepatocyte-targeting moiety. PEG modification promoted the formation of complexes with diminished aggregation, and reduced opsonization with serum proteins in the bloodstream. ${ }^{29}$ Furthermore, PEGylation provided a polyplex with improved solubility, lower cytotoxicity, and longer circulation time in vivo. ${ }^{30}$ In this paper, the synthesized GPE was characterized with proton nuclear magnetic resonance ( $\left.{ }^{1} \mathrm{H}-\mathrm{NMR}\right)$ and GPC. GPE/plasmid DNA (pDNA) complexes were prepared and investigated by particle size, zeta potential, gel retardation ability, and morphology under atomic force microscopy (AFM). Moreover, cytotoxicities of
GPE and GPE/pDNA complexes were examined in terms of cell viability, and transfection efficiencies as well as hepatocyte specificity of GPE/pDNA complexes were examined with luciferase activity assay, fluorescence microscopy, and fluorescence-activated cell-sorting analysis (FACS).

\section{Materials and methods Materials}

Branched PEI (25 kDa), lactobionic acid (LA), ethidium bromide, (EB) and 3-(4,5-dimethylthiazol-2-yl)-2,5diphenyltetrazoliumbromide (MTT) were sourced from Sigma-Aldrich (St Louis, MO, USA). PEI-Et was synthesized in our laboratory. The heterobifunctional PEG derivative $\mathrm{NH}_{2}$-PEG-COOH (molecular weight [MW] $2000 \mathrm{Da}$ ) and methoxy-PEG-succinimidyl carbonate (mPEG-sc; MW 2000 Da) were purchased from Yarebio (Shanghai, People's Republic of China). A Micro BCA protein assay kit was purchased from Thermo Fisher Scientific (Waltham, MA, USA). A luciferase assay kit was purchased from Promega (Fitchburg, WI, USA). All other chemicals used were of analytical grade.

Trypsin ethylenediaminetetraacetic acid, Dulbecco's modified Eagle's medium (DMEM), and fetal bovine serum were sourced from PAA (Cölbe, Germany). The plasmids were pEGFP-N1 (Clontech, Palo Alto, CA, USA), encoding enhanced green fluorescent protein (EGFP), and pGL3control (Promega), encoding firefly luciferase.

\section{Cell culture}

Normal rat liver cell (BRL-3A) and human cervix epithelial carcinoma cell (HeLa) were incubated in DMEM medium containing $10 \%$ fetal bovine serum at $37^{\circ} \mathrm{C}$ in a humidified atmosphere supplemented with $5 \% \mathrm{CO}_{2}$.

\section{Synthesis of GPE}

The polymer GPE was synthesized in two steps. In the first step, galactosylated PEG (Gal-PEG) was prepared by an amide-formation reaction between activated carboxyl groups of galactose bearing LA and amine groups of $\mathrm{NH}_{2}-$ PEG-COOH in accordance with a previous report, ${ }^{31}$ with some changes. Briefly, LA (1.5 mmol) dissolved in $30 \mathrm{~mL}$ of 2-( $N$-morpholino)ethanesulfonic acid (MES) buffer solution (0.1 M, pH 6.5) was activated with a mixture of N-hydroxysuccinimide (NHS) (6 mmol) and 1-ethyl-3-(3dimethylaminopropyl)-carbodiimide hydrochloride (EDC) (6 mmol). After activating the carboxyl groups for $30 \mathrm{~min}$ utes, $0.075 \mathrm{mmol}$ of PEG was added. The reaction was performed in an ice bath for 12 hours, followed by an additional 
12 hours at room temperature. Then the sample was dialyzed against distilled water in a dialysis tube (MW cutoff $1000 \mathrm{Da}$ ) for 3 days, followed by lyophilization. The resulting polymer Gal-PEG was stored at $-20^{\circ} \mathrm{C}$ for further use.

In the second step, GPE was synthesized by an amideformation reaction between activated carboxyl groups of Gal-PEG and amine groups of PEI-Et. PEI-Et was synthesized according to our previous study. ${ }^{28}$ Gal-PEG $(0.02 \mathrm{mmol})$ dissolved in $10 \mathrm{ml}$ of MES buffer solution $(0.1 \mathrm{M}, \mathrm{pH} 6.5)$ was activated with a mixture of NHS $(0.2 \mathrm{mmol})$ and EDC $(0.2 \mathrm{mmol})$. After activating the carboxyl groups for 30 minutes, $0.02 \mathrm{mmol}$ of PEI-Et was added. The reaction was performed in an ice bath for 12 hours, followed by an additional 12 hours at room temperature. Then the sample was dialyzed against distilled water in a dialysis tube (MW cutoff $3500 \mathrm{Da}$ ) for 3 days and lyophilized to obtain the polymer GPE. The reaction scheme is shown in Figure 1.

\section{Synthesis of PEG-Et}

PEI-Et $(0.04 \mathrm{mmol})$ was dissolved in $0.1 \mathrm{M}$ sodium bicarbonate, followed by the addition of $0.04 \mathrm{mmol}$ of $\mathrm{mPEG}-\mathrm{Sc}$ and stirred for 4 hours at room temperature. The resultant
PEG-Et was dialyzed against distilled water in a dialysis tube (MW cutoff $3500 \mathrm{Da}$ ) for 2 days, followed by lyophilization. The resulting polymer PEG-Et was stored at $-20^{\circ} \mathrm{C}$ for further use.

\section{Characterization of GPE}

${ }^{1} \mathrm{H}-\mathrm{NMR}$ spectra of GPE were recorded on a Varian Unity $300 \mathrm{MHz}$ spectrometer (Mercury plus 400; Varian, Palo Alto, CA, USA), using $\mathrm{D}_{2} \mathrm{O}$ as a solvent. GPC relative to PEG standards (molecular weight range Mp 106, 430, 633, 1400, $4290,7130,12,600,20,600 \mathrm{Da})$ was used to measure the MW of GPE by a Waters (Milford, MA, USA) high-pressure liquid chromatography (HPLC) system. The mobile phase of HPLC was formic acid.

\section{Preparation of polymer/pDNA complexes}

Both pDNA and polymer were separately diluted to the required concentration in phosphate-buffered saline (PBS; $\mathrm{pH}$ 7.4). After that, the polymer/pDNA complexes were prepared by adding polymer solution to the pDNA solution at the desired weight ratio with gentle vortexing. The polymer/ pDNA complexes were incubated at room temperature for 30 minutes prior to use.
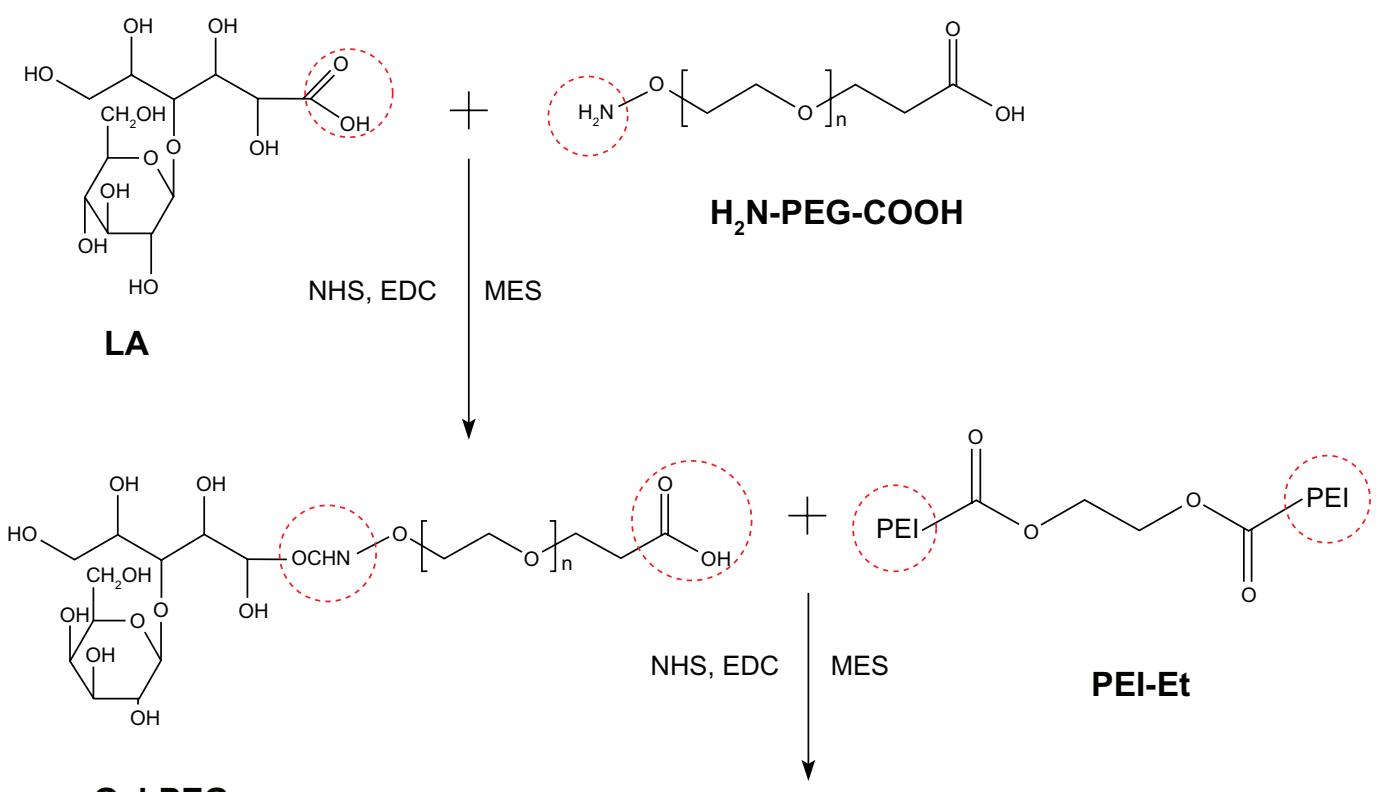

Gal-PEG

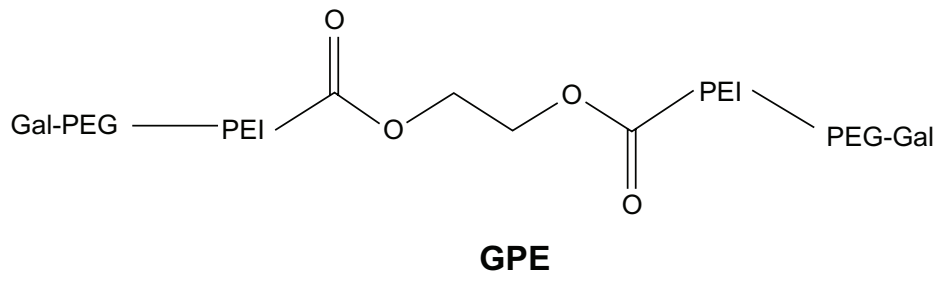

Figure I Reaction scheme of galactosylated poly(ethylene glycol)-graft-polyethylenimine derivative (GPE).

Abbreviations: PEI-Et, biscarbamate cross-linked polyethylenimine derivative; PEG, poly(ethylene) glycol; Gal-PEG, galactosylated PEG; LA, lactobionic acid. 


\section{Gel retardation assay}

The gel retardation ability of GPE was evaluated using agarose gel electrophoresis with pEGFP-N1. GPE and pDNA solutions were mixed at various weight ratios from 1 to 70 and incubated for 30 minutes at room temperature. The complexes and naked pDNA were electrophoresed on $1 \%(\mathrm{w} / \mathrm{v})$ agarose gels pretreated with $\mathrm{EB}(0.5 \mu \mathrm{g} / \mathrm{mL}$ of the gel $)$ in $1 \times$ Tris-acetate buffer at $80 \mathrm{~V}$ for 40 minutes.

\section{Particle-size and zeta-potential measurements}

A particle-size analyzer (90Plus; Brookhaven Instruments, Holtsville, NY, USA) was used to examine the particle size and zeta potential of GPE/pDNA complexes. GPE/pDNA complexes at various $\mathrm{w} / \mathrm{w}$ ratios from 1 to 70 were prepared and incubated for 30 minutes at room temperature before measurement. Each sample was performed in triplicate.

\section{Atomic force microscopy}

The morphology of GPE/pDNA complexes at w/w 70 was examined under AFM (E-Sweep; Hitachi High-Tech Science, Tokyo, Japan). The complexes were deposited on a mica disk and dried for 3 hours at room temperature. Then it was observed under AFM.

\section{Cytotoxicity assay}

Cytotoxicity evaluation of the polymer was measured with MTT assay. PEI $25 \mathrm{kDa}$ was used as a control. BRL-3A cells were grown in 96-well plates at an initial density of 5000 cells/well in $100 \mu \mathrm{L}$ of DMEM and incubated for 24 hours. After that, the media were changed with fresh serum-free DMEM pretreated with polymers at various concentrations $(5,10,20,50$, and $100 \mu \mathrm{g} / \mathrm{mL})$ or polymer/ pDNA complexes at various $\mathrm{w} / \mathrm{w}$ ratios $(2,5,10,20,30$, and 50). After further incubation for 4 hours, the media were replaced with fresh serum-free DMEM, and $25 \mu \mathrm{L}$ MTT solution ( $5 \mathrm{mg} / \mathrm{mL}$ in PBS) was added per well. After an additional incubation for 6 hours, $150 \mu \mathrm{L}$ of DMSO was added. Then the plate was agitated for 15 minutes. Finally, the absorbance was recorded with an enzyme-linked immunosorbent assay reader (MK3; Thermo Fisher Scientific) at $570 \mathrm{~nm}$ (with $630 \mathrm{~nm}$ as a reference wavelength). The data from five separate experiments were expressed as a percentage of viable cells over untreated control.

\section{In vitro transfection experiments}

The transfections mediated by GPE were performed in BRL-3A and HeLa cells. Cells were grown in 48-well plates at an initial density of $5 \times 10^{4}$ cells/well in $500 \mu \mathrm{L}$ of DMEM and incubated for 24 hours. After that, wells were washed with PBS, and polymer/pGL3-control (500 ng) complexes at desired w/w ratios were added to the cells. After an additional incubation for 4 hours, the media were replaced with fresh and complete DMEM and allowed to incubate for 44 hours. Luciferase assays were performed according to the manufacturer's suggested protocol (Promega). The luciferase activity was expressed in terms of relative light units $/ \mathrm{mg}$ protein. Each sample was performed in triplicate. The optimal w/w ratio of GPE/pEGFP-N1 complexes from the luciferase activity assay was selected for the GFP-expression experiment. The transfection efficiency was estimated by scoring the percentage of cells expressing GFP using a FACSCalibur system (BD, Franklin Lakes, NJ, USA). Each sample was performed in triplicate. The data were presented as means \pm standard deviation. For the competition assay, BRL-3A cells were preincubated with galactose $(1,10$, and $100 \mathrm{mM}$ ) for 15 minutes, then the cells were incubated with GPE/pDNA and PEG-Et/pDNA complexes for 3 hours. The luciferase activity was determined as described above after 45 hours' further incubation. ${ }^{28}$

\section{Statistical analysis}

Data were expressed as means \pm standard deviation. Statistical analysis was performed with SPSS software (v 19.0; IBM, Armonk, NY, USA). Student's $t$-test (twotailed) was used to test the significance of the differences between two groups. Data were considered significantly different at the level of $P<0.05$ and very significantly different at the level of $P<0.01$.

\section{Results and discussion GPE was successfully synthesized}

Figure 1 schematically illustrates the procedures for the synthesis of GPE. The intermediate Gal-PEG was synthesized by an amide-formation reaction between activated carboxyl groups of LA and amine groups of $\mathrm{NH}_{2}-\mathrm{PEG}-\mathrm{COOH}$, and the resulting polymer GPE was synthesized by an amideformation reaction between activated carboxyl groups of Gal-PEG and amine groups of PEI-Et. The structure of GPE was confirmed using ${ }^{1} \mathrm{H}-\mathrm{NMR}$. As shown in Figure 2, the proton peaks appeared at $2.4-3.3 \mathrm{ppm}$ in the GPE attributed to PEI ( $\left.-\mathrm{NHCH}_{2} \mathrm{CH}_{2}-\right)$, indicating that PEI-Et was successfully conjugated to the Gal-PEG chain. The weight-average MW of GPE measured with GPC was $9489 \mathrm{Da}$, with a polydispersity of 1.44. These results indicated that GPE was successfully synthesized. 


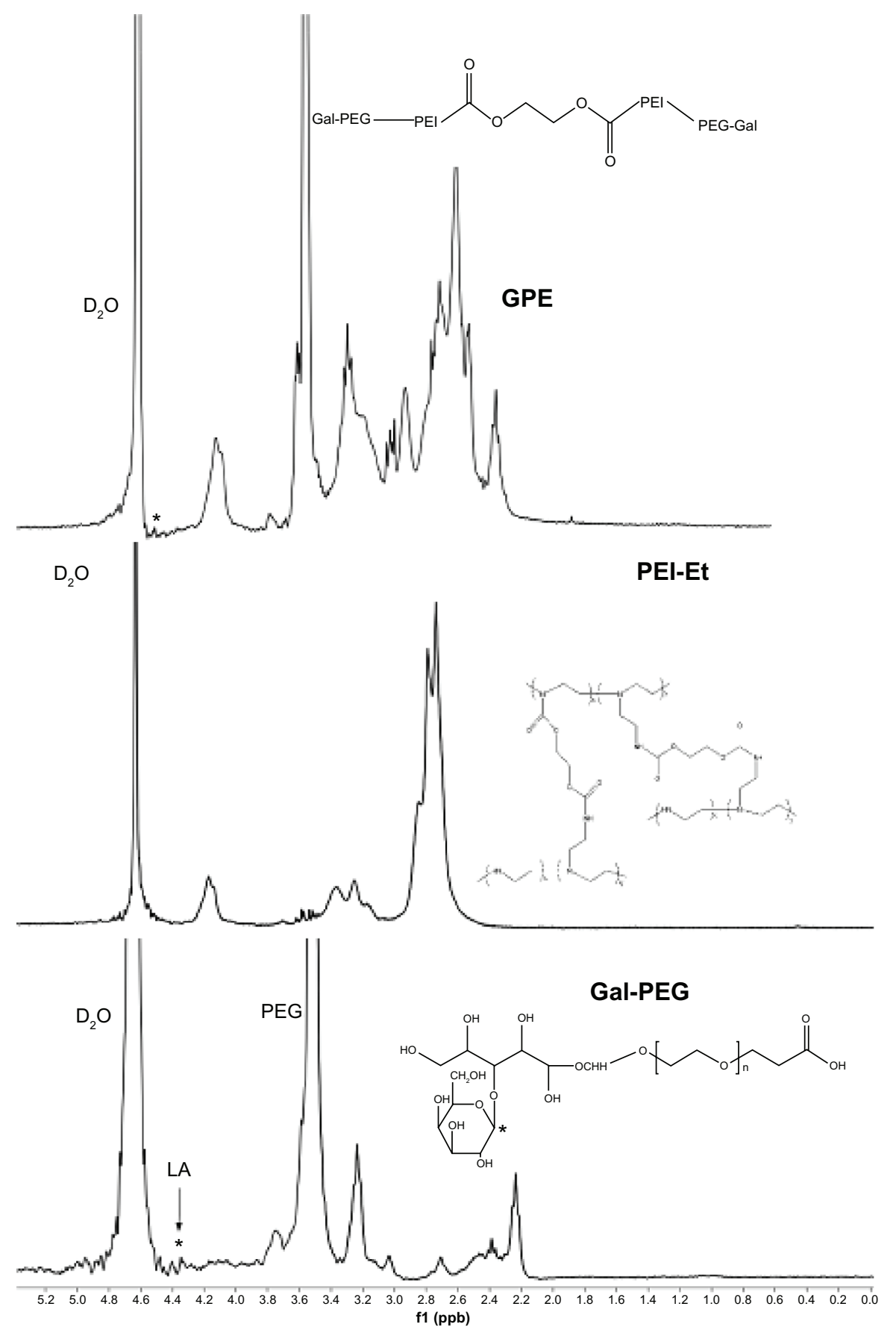

Figure 2 Representative proton nuclear magnetic resonance spectra of galactosylated poly(ethylene glycol)-graft-polyethylenimine derivative (GPE).

Abbreviations: PEI-Et, biscarbamate cross-linked polyethylenimine derivative; PEG, poly(ethylene) glycol; Gal-PEG, galactosylated PEG; LA, lactobionic acid.

\section{Characterization of GPE/pDNA complexes was appropriate for cellular uptake}

As for cationic polymers, the condensation of pDNA into small particles is an important prerequisite for gene delivery. ${ }^{32}$ The gel retardation ability of GPE was measured with agarose gel electrophoresis. Naked pDNA was used as the control group. As indicated in Figure 3, GPE completely retarded the migration of $\mathrm{pDNA}$ when the $\mathrm{w} / \mathrm{w}$ ratio was 3 , suggesting that
GPE/pDNA complexes were completely formed at $\mathrm{w} / \mathrm{w}$ ratios over 3. Interaction of cationic polymers with nucleic acid could protect the nucleic acid from enzymatic degradation, ${ }^{33,34}$ which facilitated efficient gene transfection.

The particle size of the polymer/pDNA complexes was an important factor for hepatocyte gene delivery. As Hashida et al mentioned, the majority of the fenestrate of the liver sinusoid was smaller than $200 \mathrm{~nm}$ in diameter. ${ }^{35}$ Therefore, it was hard 


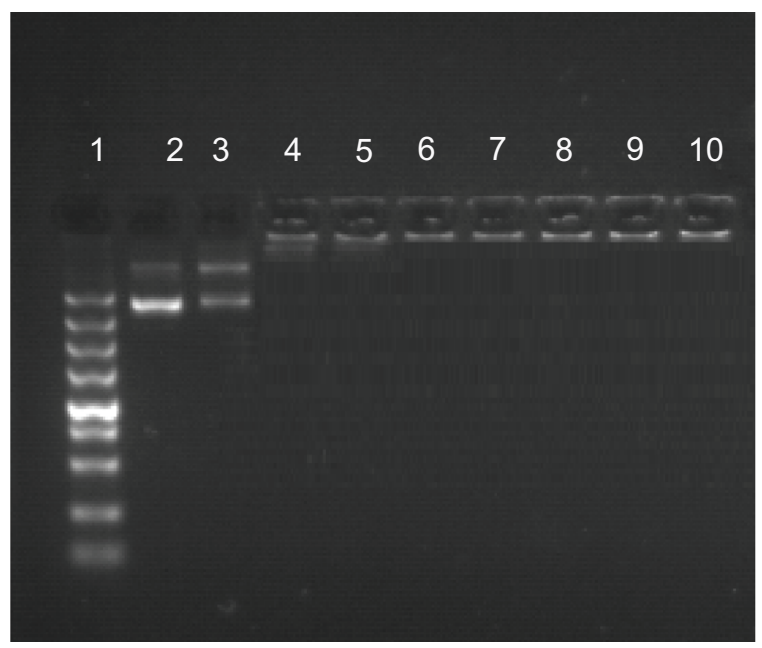

Figure 3 Agarose gel electrophoresis of galactosylated poly(ethylene glycol)-graftpolyethylenimine derivative/plasmid DNA (pDNA) complexes at various w/w ratios. Notes: Lane I, marker; lane 2, naked pDNA; lanes 3-10, polymer/pDNA complexes at $\mathrm{w} / \mathrm{w}$ ratios of $\mathrm{I}, 3,5,10,20,30,50$, and 70 .

for large particles to arrive at the parenchymal cells of the liver. In addition, gene carriers with diameters larger than $200 \mathrm{~nm}$ are readily scavenged nonspecifically by monocytes and the reticuloendothelial system. ${ }^{36}$ A positive surface charge of GPE, which comes from the protonated amino groups on PEI, may be an advantage for cellular uptake, due to the electrostatic interaction between the negatively charged cellular membrane and the positively charged complexes. ${ }^{37,38}$ As shown in Figure 4, at a w/w ratio of 1 , the particle size of GPE/pDNA complexes was $108 \mathrm{~nm}$ and the zeta potential was $-8.9 \mathrm{mV}$, indicating that the complexation between GPE and pDNA was incomplete. However, when the w/w ratios were over 5, GPE could condense pDNA into nanoparticles with relatively constant diameters of 79-100 nm, implying that stable complexes were formed with a size appropriate for cellular uptake. Meanwhile, zeta potential ranged from $6 \mathrm{mV}$ to $15 \mathrm{mV}$. These results accorded well with the results of the gel retardation assay.

The representative morphologies of GPE/pDNA complexes (w/w 70) under AFM are shown in Figure 5. The results show that the complexes appeared spherical in shape with compact structure, and the diameters of the complexes ranged from $53 \mathrm{~nm}$ to $65 \mathrm{~nm}$, smaller than those determined by dynamic light scattering. This phenomenon was possibly due to the shrinkage of the PEG shell caused by the evaporation of water during drying before AFM examination. ${ }^{39}$

\section{GPE showed low cytotoxicity in BRL-3A cells}

For polycationic gene carriers, cytotoxicity was a main hurdle for clinical application. ${ }^{40}$ The cytotoxicity associated with
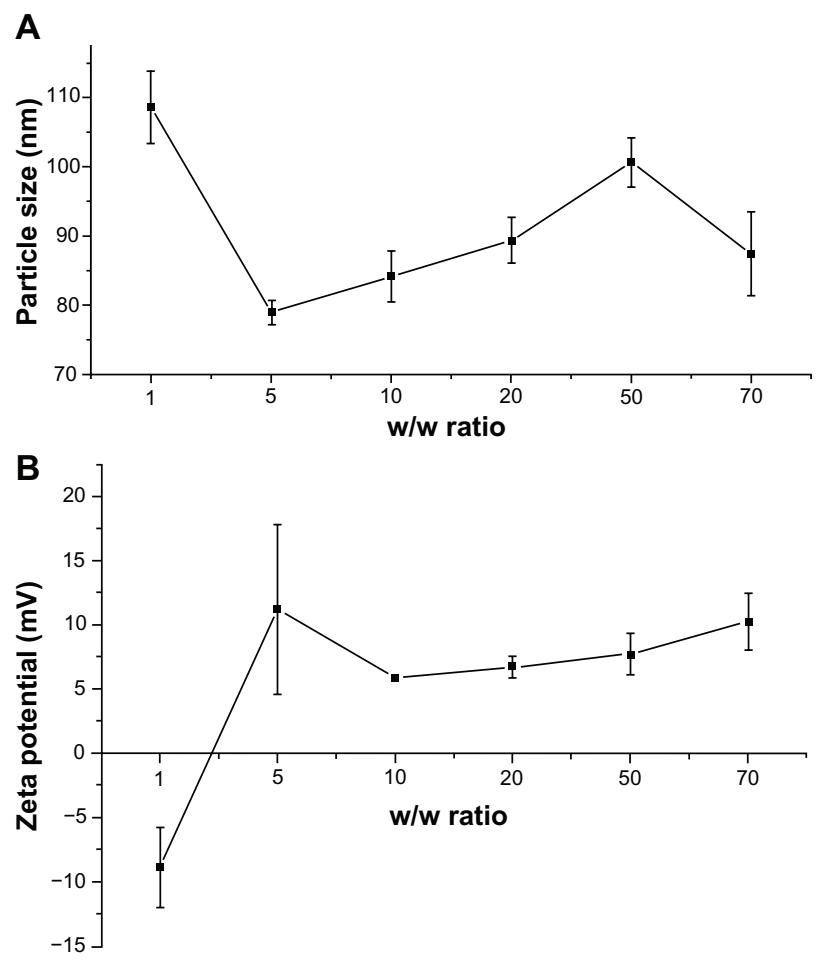

Figure 4 Particle size (A) and zeta potential (B) of galactosylated poly(ethylene glycol)graft-polyethylenimine derivative/plasmid DNA complexes, as determined by dynamic light scattering at various $\mathrm{w} / \mathrm{w}$ ratios.

Note: $\mathrm{n}=3$, error bars represent standard deviation.

GPE could be divided into two types: the immediate toxicity mediated by free GPE, and the delayed toxicity mediated by GPE/pDNA complexes. For this reason, cell viabilities of free GPE and GPE/pDNA complexes were assayed using BRL-3A cells. Free polymers were used in order to mimic a worst-case scenario and get much larger sensitivity results, because cytotoxicity was remarkably reduced with formation of polymer/pDNA complexes. ${ }^{41}$

As shown in Figure 6, cytotoxicity of GPE was much lower than PEI $25 \mathrm{kDa}$ at the same concentration. In addition, GPE displayed negligible cytotoxicity at concentrations below $100 \mu \mathrm{g} / \mathrm{mL}$. The cell viabilities were $104 \% \pm 7 \%$ at a polymer concentration of $5 \mu \mathrm{g} / \mathrm{mL}$. The value slightly decreased to $95 \% \pm 6 \%$ with GPE concentration increasing to $100 \mu \mathrm{g} / \mathrm{mL}$, implying that a wide dose range of GPE may be used for gene transfection. In contrast, with increasing concentrations of PEI $25 \mathrm{kDa}$, cell viability decreased drastically. For example, cell viability was from $88 \% \pm 3 \%$ at a PEI $25 \mathrm{kDa}$ concentration of $5 \mu \mathrm{g} / \mathrm{mL}$ to $23 \% \pm 1 \%$ at a PEI $25 \mathrm{kDa}$ concentration of $100 \mu \mathrm{g} / \mathrm{mL}$. In the case of the cell viabilities of polymer/pDNA complexes, GPE/pDNA complexes also showed dramatically lower cytotoxicity than PEI $25 \mathrm{kDa} /$ pDNA complexes. These results suggested that the immediate toxicity and the delayed toxicity of GPE were all lower 

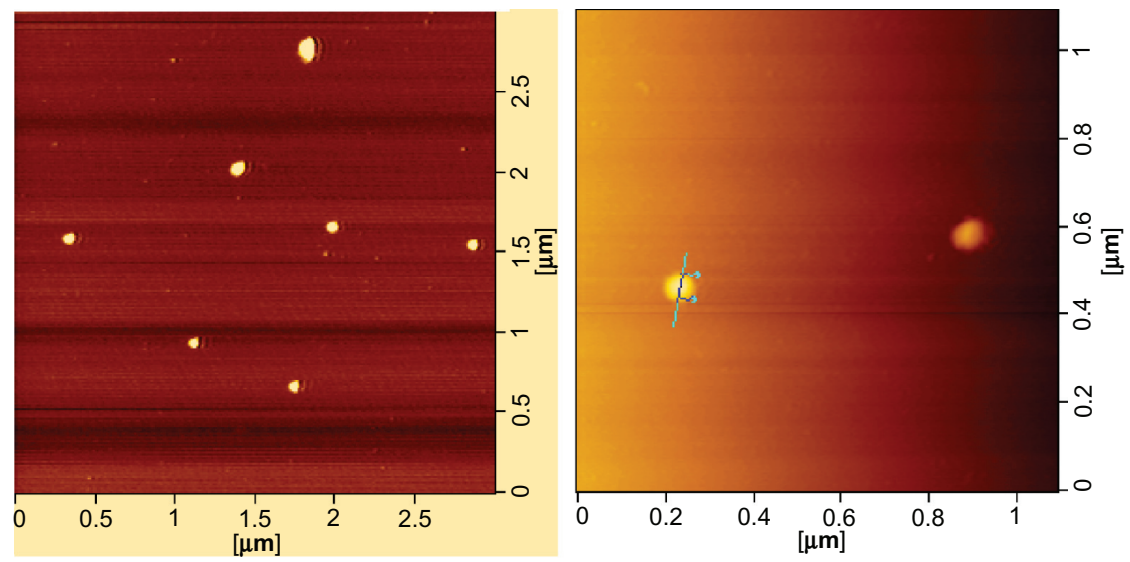

$[\mathrm{nm}]$

\begin{tabular}{|r|r|r|r|r|r|}
\hline & $\mathrm{Z} 1[\mathrm{~nm}]$ & $\mathrm{Z} 2[\mathrm{~nm}]$ & $\Delta \mathrm{Z}[\mathrm{nm}]$ & Distance [nm] & \multicolumn{1}{c|}{$\left.\Phi{ }^{\circ}\right]$} \\
\hline & $\mathbf{1 6 . 4 7}$ & $\mathbf{1 6 . 4 2}$ & $\mathbf{0 . 0 5}$ & $\mathbf{5 3 . 3 7}$ & $\mathbf{0 . 1}$ \\
\hline & & & & & \\
\hline & & & & & \\
\hline & & & & & \\
\hline & & & & & \\
\hline
\end{tabular}

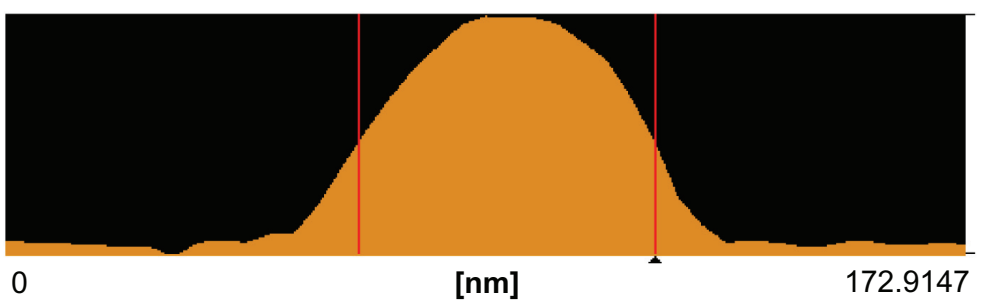

22.94

[nm]

10.51

Figure 5 Representative atomic force microscopic image of galactosylated poly(ethylene glycol)-graft-polyethylenimine derivative/plasmid DNA complexes at a w/w ratio of 70.

than that of PEI $25 \mathrm{kDa}$, which demonstrated that GPE was a significantly promising carrier for safe gene transfer.

According to previous studies, chemical modification of PEI with PEG could help reduce the cytotoxicity by reducing the number of PEI amino groups. ${ }^{42,43}$ Therefore, GPE with much lower cytotoxicity than PEI $25 \mathrm{kDa}$ was probably due to the properties of the hydrophilic groups of PEG. In addition, Bieber and Elsässer reported that a positive correlation existed between MW and cytotoxicity of PEI: cytotoxicity of PEI with low MW was much lower than PEI with high $\mathrm{MW} .^{44}$ For this reason, the lower molecular weight of GPE was another factor that produced lower cytotoxicity than PEI $25 \mathrm{kDa}$.

\section{GPE exhibited high transfection efficiency and good hepatocyte specificity in BRL-3A cells}

To observe the in vitro transfection efficiency and hepatocyte specificity of GPE, BRL-3A and HeLa cells were transfected with polymer/pDNA complexes with various $w / w$ ratios. PEI $25 \mathrm{kDa}$ at optimal w/w ratio was used as a positive control.
As illustrated in Figure 7A, the transfection efficiency was dependent on the GPE/pDNA weight ratio. Transfection efficiency of GPE increased with increasing w/w ratios below 70, and then decreased at higher w/w ratios. A reasonable explanation may be as follows: a low w/w ratio would produce unstable complexes and low transfection efficiency; however, a high $\mathrm{w} / \mathrm{w}$ ratio yielded low transfection efficiency due to the stability, because the pDNA could not be released from the complexes. ${ }^{28}$ In addition, the transfection efficiency of GPE was higher than that of PEI $25 \mathrm{kDa}$ at w/w from 30 to $70(P<0.05)$. As for the naked pDNA, it produced almost negligible luciferase activity, indicating that pDNA without any vector showed significantly low transfection efficiency, which was in agreement with the previous study. ${ }^{45,46}$ As illustrated in Figure 7B, transfection efficiency of GPE was 4.6-fold higher than that of PEG-Et at a w/w ratio of 70 in BRL-3A cells $(P<0.01)$. Moreover, GPE showed a 13.2-fold higher transfection efficiency in BRL-3A cells in comparison to HeLa cells $(P<0.01)$, which did not express ASGPR, suggesting that the attachment of galactose residues in GPE might be beneficial for the recognition of ASGPR and lead 
A

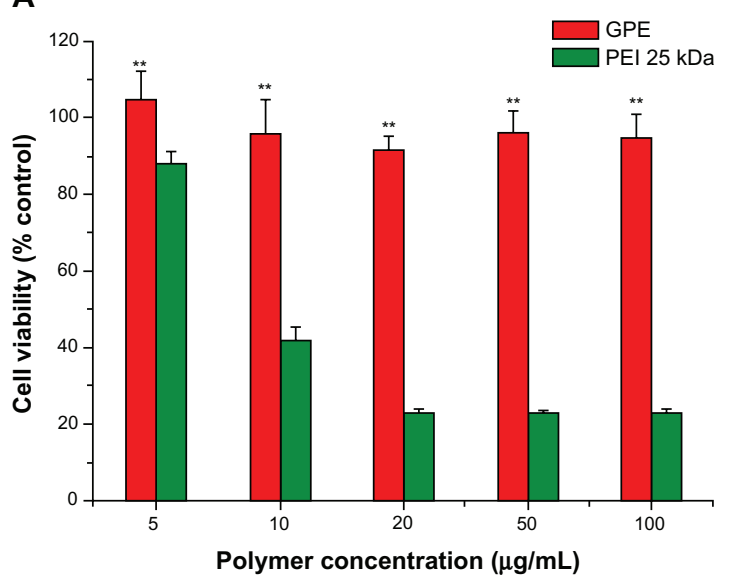

B

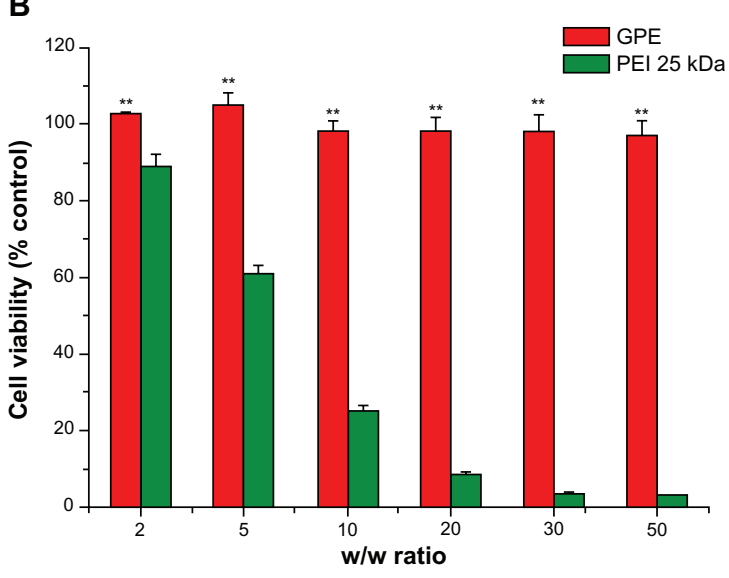

Figure 6 Cytotoxicity of the polymers at various concentrations (A) and cytotoxicity of the polymer/plasmid DNA complexes at various $\mathrm{w} / \mathrm{w}$ ratios $(\mathbf{B})$ in BRL-3A cell lines.

Notes: $* * P<0.01$ vs PEI $25 \mathrm{kDa} ; \mathrm{n}=5$; error bars represent standard deviation. Abbreviations: GPE, galactosylated poly(ethylene glycol)-graft-polyethylenimine derivative; PEI, polyethylenimine.

A

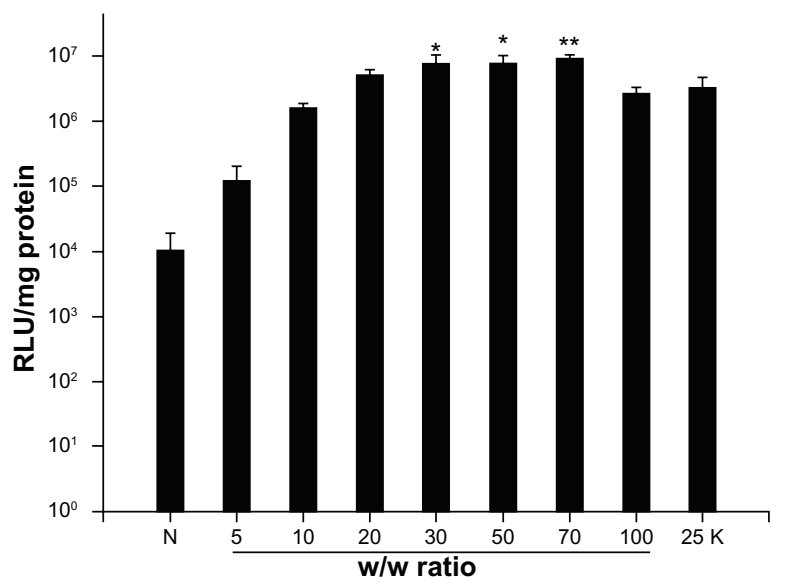

to the significant improvement of transfection efficiency in BRL-3A cells.

To confirm the hepatocyte specificity of GPE, genetransfection efficiency was evaluated in BRL-3A and HeLa cells, using pEGFP-N1 as a reporter gene. Figure 8A displays typical fluorescence microscope images; BRL-3A cells transfected with GPE/pEGFP-N1 showed more bright fluorescent spots than PEG-Et/pEGFP-N1. In addition, transfection efficiency was monitored by flow cytometry. As shown in Figure 8C, GPE exhibited higher efficiency (33\%) than PEG-Et $(27 \%)$ in BRL-3A cells $(P<0.01)$. Also, transfection efficiency of GPE was higher in BRL-3A cells $(33 \%)$ than in HeLa cells $(26 \%)(P<0.01)$. These results obtained also confirmed the results of luciferase activity assays, implying that GPE showed good hepatocyte specificity.

To confirm further the effect of galactose on receptor-mediated gene delivery, the competition assay was performed at the presence of free galactose $(1,10$, and $100 \mathrm{mM}$ ) as a competitor. Figure 9 shows that the transfection efficiency of GPE in BRL-3A cells was reduced in the presence of free galactose. Especially, inhibition of the transfection efficiency of GPE in the presence of galactose depended on concentration of pretreated galactose, whereas the phenomenon was not observed on the transfection efficiency of PEG-Et. Transfection efficiency when using PEG-Et as a carrier was very low and was not affected irrespective of the addition of free galactose. These results indicated that pretreatment of free galactose as a competitor could reduce cellular uptake of GPE by competitive binding

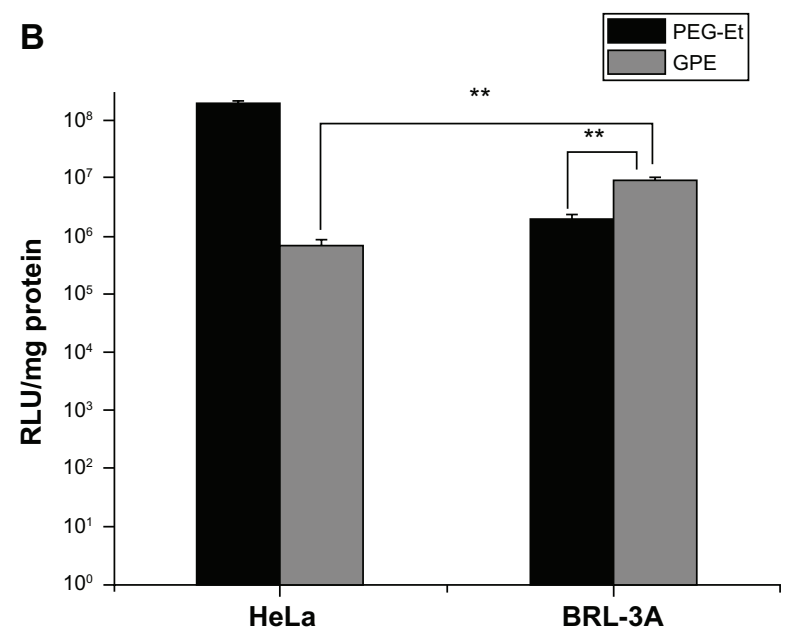

Figure 7 (A) Transfection efficiency of GPE/pGL3-control complexes at various w/w ratios in BRL-3A cell lines, in comparison with that of polyethylenimine 25 kDa (w/w 2). (B) Transfection efficiency of galactosylated poly(ethylene glycol)-graft-polyethylenimine derivative (GPE)/PGL3-control and poly(ethylene) glycol (PEG)-Et/PGL3-control complexes prepared at a w/w ratio of 70 in HeLa and BRL-3A cells.

Notes: $* P<0.05$; $* * P<0.0$ I; N: naked plasmid DNA; $25 \mathrm{~K}$ : polyethylenimine $25 \mathrm{kDa} ; \mathrm{n}=3$; error bars represent standard deviation.

Abbreviation: RLU, relative light units. 

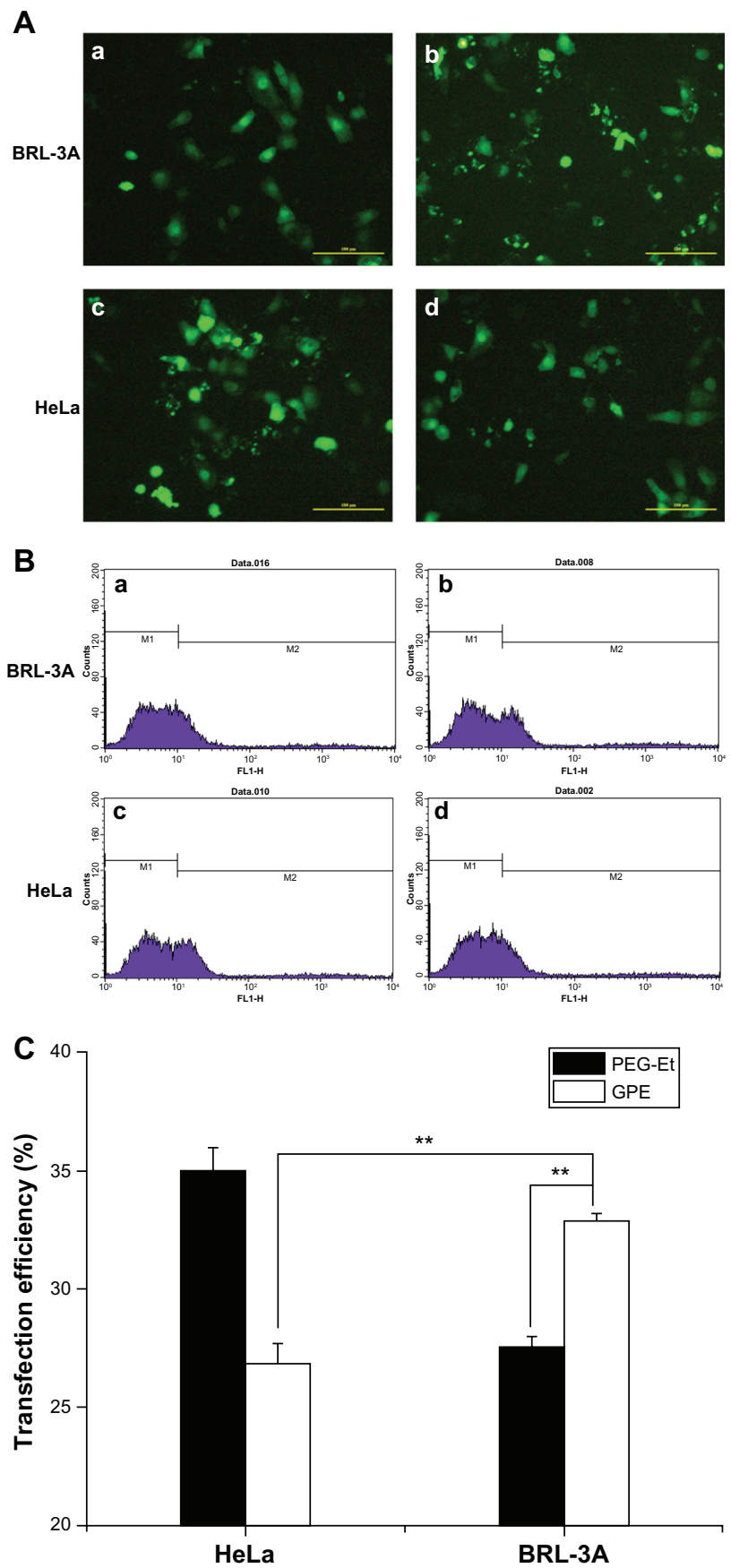

Figure 8 Typical fluorescence images (magnification 100×) (A) and flow cytometry analyzed graphs (B) of cell distribution expressing GFP of BRL-3A and HeLa cells transfected with PEG-Et/pEGFP-NI (a and $\mathbf{c}$ ), and GPE/pEGFP-NI (b and d) at w/w 70, and (C) transfection efficiency of PEG-Et and GPE as a percentage of EGFP positive cells per total amount of cells.

Notes: ${ }^{* * P}<0.01 ; \mathrm{n}=3$; error bars represent standard deviation.

Abbreviations: PEG, poly(ethylene glycol); GPE, galactosylated poly(ethylene glycol)graft-polyethylenimine derivative; pEGFP, plasmid enhanced green fluorescent protein.

to ASGPR on the cell surface, although the inhibition of transfection efficiency was incomplete in the competition assay, because GPE still entered into BRL-3A cells via both nonspecific endocytosis and receptor-mediated endocytosis.

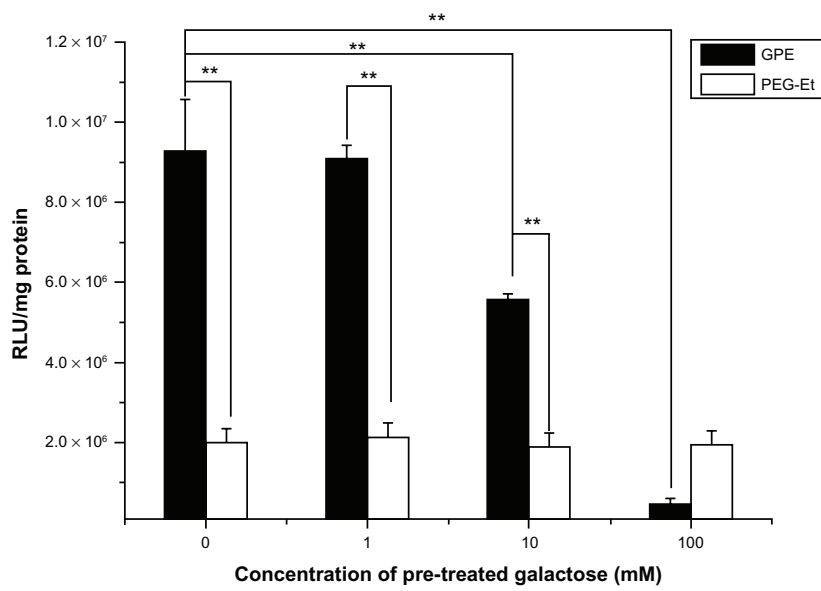

Figure 9 Competition assay of GPE/PGL3-control complexes on BRL-3A cells prepared at a $\mathrm{w} / \mathrm{w}$ ratio of 70 by adding free galactose $(\mathrm{I}, 10$, and $100 \mathrm{mM})$ as a competitor of the galactose functional group in GPE.

Notes: $* * P<0.01 ; n=3$; error bars represent standard deviation.

Abbreviations: PEG, poly(ethylene glycol); GPE, galactosylated poly(ethylene glycol)-graft-polyethylenimine derivative; RLU, relative light units.

\section{Conclusion}

In the current study, a novel hepatocyte-targeting gene carrier, GPE, was successfully prepared. The polymer was constructed by a simple procedure, possessed a enhanced ability to condense pDNA effectively into nanoparticles with physicochemical properties appropriate for cellular uptake. GPE displayed significantly higher transfection efficiency and much lower cytotoxicity than commercially available PEI $25 \mathrm{kDa}$ in BRL-3A cells. Importantly, GPE exhibited good hepatocyte specificity. To sum up, it is reasonable to conclude that GPE might carry potential for efficient and safe hepatocyte-targeting gene delivery.

\section{Acknowledgments}

This study was supported by grants from the National Natural Science Foundation of China (81001416 and 81270205), the Shanghai Science and Technology Committee, People's Republic of China (10JC1408902), and the Research Fund for Integrated Medicine and Engineering of Shanghai Jiao Tong University (YG2011MS21).

\section{Disclosure}

The authors report no conflicts of interest in this work.

\section{References}

1. Srinivas R, Samanta S, Chaudhuri A. Cationic amphiphiles: promising carriers of genetic materials in gene therapy. Chem Soc Rev. 2009;38: 3326-3338.

2. Park TG, Jeong JH, Kim SW. Current status of polymeric gene delivery systems. Adv Drug Deliv Rev. 2006;58:467-486. 
3. Niidome T, Urakawa M, Sato H, et al. Gene transfer into hepatoma cells mediated by galactose-modified alpha-helical peptides. Biomaterials. 2000;21:1811-1819.

4. Mintzer MA, Simanek EE. Nonviral vectors for gene delivery. Chem Rev. 2009;109:259-302.

5. Yu H, Wagner E. Bioresponsive polymers for nonviral gene delivery. Curr Opin Mol Ther. 2009;11:165-178.

6. Heinze M, Brezesinski G, Dobner B, Langner A. Novel cationic lipids based on malonic acid amides backbone: transfection efficiency and cell toxicity properties. Bioconjug Chem. 2010;21:696-708.

7. Yang XZ, Dou S, Sun TM, Mao CQ, Wang HX, Wang J. Systemic delivery of siRNA with cationic lipid assisted PEG-PLA nanoparticles for cancer therapy. J Control Release. 2011;156:203-211.

8. Sato T, Ishii T, Okahata Y. In vitro gene delivery mediated by chitosan. effect of $\mathrm{pH}$, serum, and molecular mass of chitosan on the transfection efficiency. Biomaterials. 2001;22:2075-2080.

9. Fischer D, Li Y, Ahlemeyer B, Krieglstein J, Kissel T. In vitro cytotoxicity testing of polycations: influence of polymer structure on cell viability and hemolysis. Biomaterials. 2003;24:1121-1131.

10. Dong X, Tian H, Chen L, Chen J, Chen X. Biodegradable mPEGb-P(MCC-g-OEI) copolymers for efficient gene delivery. $J$ Control Release. 2011;152:135-142.

11. Sun TM, Du JZ, Yan LF, Mao HQ, Wang J. Self-assembled biodegradable micellar nanoparticles of amphiphilic and cationic block copolymer for siRNA delivery. Biomaterials. 2008;29:4348-4355.

12. Eliyahu H, Joseph A, Azzam T, Barenholz Y, Domb AJ. Dextranspermine-based polyplexes - evaluation of transgene expression and of local and systemic toxicity in mice. Biomaterials. 2006;27: 1636-1645

13. Xia J, Tian H, Chen L, et al. Oligoethylenimines grafted to PEGylated poly( $\beta$-amino ester)s for gene delivery. Biomacromolecules. 2011;12:1024-1031.

14. Kaneda Y. Gene therapy: a battle against biological barriers. Curr Mol Med. 2001;1:493-499.

15. Jeong JH, Lee M, Kim WJ, et al. Anti-GAD antibody targeted nonviral gene delivery to islet beta cells. J Control Release. 2005;107: $562-570$.

16. Mansouri S, Cuie Y, Winnik F, et al. Characterization of folatechitosan-DNA nanoparticles for gene therapy. Biomaterials. 2006;27: 2060-2065

17. Cho KC, Jeong JH, Chung HJ, Joe CO, Kim SW, Park TG. Folate receptor-mediated intracellular delivery of recombinant caspase-3 for inducing apoptosis. J Control Release. 2005;108:121-131.

18. Hashimoto M, Morimoto M, Saimoto H, Shigemasa Y, Sato T. Lactosylated chitosan for DNA delivery into hepatocytes: the effect of lactosylation on the physicochemical properties and intracellular trafficking of pDNA/chitosan complexes. Bioconjug Chem. 2006;17: 309-316.

19. Cook SE, Park IK, Kim EM, et al. Galactosylated polyethyleniminegraft-poly(vinyl pyrorolidone) as a hepatocytetargeting gene carrier. $J$ Control Release. 2005;105:151-163.

20. Kim TH, Park IK, Nah JW, Choi YJ, Cho CS. Galactosylated chitosan/ DNA nanoparticles prepared using water-soluble chitosan as a gene carrier. Biomaterials. 2004;25:3783-3792.

21. Hashimoto M, Morimoto M, Saimoto H, et al. Gene transfer by DNA/ mannosylated chitosan complexes into mouse peritoneal macrophages. Biotechnol Lett. 2006;28:815-821.

22. Lee H, Kim TH, Park TG. A receptor-mediated gene delivery system using streptavidin and biotin-derivatized, pegylated epidermal growth factor. J Control Release. 2002;83:109-119.

23. Sakaguchi N, Kojima C, Harada A, et al. Enhancement of transfection activity of lipoplexes by complexation with transferrin-bearing fusogenic polymer-modified liposomes. Int J Pharm. 2006;325:186-190.

24. Schwartz AL, Fridovich SE, Knowles BB, Lodish HF. Characterization of the asialoglycoprotein receptor in a continuous hepatoma line. J Biol Chem. 1981;256:8878-8881.
25. Gref R, Rodrigues J, Couvreur P. Polysaccharides grafted with polyesters: novel amphiphilic copolymers for biomedical applications. Macromolecules. 2002;35:9861-9867.

26. Gao S, Chen J, Xu X, et al. Galactosylated low molecular weight chitosan as DNA carrier for hepatocyte-targeting. Int J Pharm. 2003;255:57-68.

27. Kim EM, Jeong HJ, Park IK, et al. Asialoglycoprotein receptor targeted gene delivery using galactosylated polyethyleniminegraft-poly(ethylene glycol): in vitro and in vivo studies. $J$ Control Release. 2005;108:557-567.

28. Wang YQ, Su J, Wu F, et al. Biscarbamate cross-linked polyethylenimine derivative with low molecular weight, low cytotoxicity and high efficiency for gene delivery. Int J Nanomedicine. 2012;7:693-704.

29. Oba M, Miyata K, Osada K, et al. Polyplex micelles prepared from u-cholesteryl PEG-polycation block copolymers for systemic gene delivery. Biomaterials. 2011;32:652-663.

30. Neu M, Germershaus O, Behe M, Kissel T. Bioreversibly crosslinked polyplexes of PEI and high molecular weight PEG show extended circulation times in vivo. $J$ Control Release. 2007;124: 69-80.

31. Jiang HL, Kwon JT, Kim EM, et al. Galactosylated poly(ethylene glycol)-chitosan-graft-polyethylenimine as a gene carrier for hepatocyte-targeting. J Control Release. 2008;131:150-157.

32. Neu M, Fischer D, Kissel T. Recent advances in rational gene transfer vector design based on poly(ethylene imine) and its derivatives. J Gene Med. 2005;7:992-1009.

33. Harada A, Togawa H, Kataoka K. Physicochemical properties and nuclease resistance of antisense-oligonucleotides entrapped in the core of polyion complex micelles composed of poly(ethylene glycol)-poly (L-lysine) block copolymers. Eur J Pharm Sci. 2001;13:35-42.

34. Jeong JH, Kim SW, Park TG. Novel intracellular delivery system of antisense oligonucleotide by self assembled hybrid micelles composed of DNA/PEG conjugate and cationic fusogenic peptide. Bioconjug Chem. 2003;14:473-479.

35. Hashida M, Takemura S, Nishikawa M, Takakura Y. Targeted delivery of plasmid DNA complexed with galactosylated poly(L-lysine). J Control Release. 1998;53:301-310.

36. Litzinger DC, Buiting AM, van Rooijen N, Huang L. Effect of liposome size on the circulation time and intraorgan distribution of amphipathic poly(ethylene glycol)-containing liposomes. Biochim Biophys Acta. 1994;1190:99-107.

37. Patiño T, Nogués C, Ibáñez E, Barrios L. Enhancing microparticle internalization by nonphagocytic cells through the use of noncovalently conjugated polyethyleneimine. Int J Nanomedicine. 2012;7: 5671-5682.

38. Xu Z, Chen L, Gu W, et al. The performance of docetaxel-loaded solid lipid nanoparticles targeted to hepatocellular carcinoma. Biomaterials. 2009;30:226-232.

39. Suo A, Qian J, Yao Y, Zhang W. Galactosylated poly(ethylene glycol)b-poly (1-lactide-co- $\beta$-malic acid) block copolymer micelles for targeted drug delivery: preparation and in vitro characterization. Int $J$ Nanomedicine. 2010;5:1029-1038.

40. Lv H, Zhang S, Wang B, Cui S, Yan J. Toxicity of cationic lipids and cationic polymers in gene delivery. J Control Release. 2006; 114:100-109.

41. Kunath K, von Harpe A, Fischer D, et al. Low-molecular-weight polyethylenimine as a non-viral vector for DNA delivery: comparison of physicochemical properties, transfection efficiency and in vivo distribution with high-molecular-weight polyethylenimine. J Control Release. 2003;89:113-125.

42. Zhang X, Pan SR, Hu HM, et al. Poly(ethylene glycol)-blockpolyethylenimine copolymers as carriers for gene delivery: effects of PEG molecular weight and PEGylation degree. J Biomed Mater Res A. 2008;84:795-804.

43. Kostarelos K. Rational design and engineering of delivery systems for therapeutics: biomedical exercises in colloid and surface science. $A d v$ Colloid Interface Sci. 2003;106:147-168. 
44. Bieber T, Elsässer HP. Preparation of a low molecular weight polyethylenimine for efficient cell transfection. Biotechniques. 2001;30:74-77, 80-81.

45. Gao Y, Zhang Z, Chen L, Gu W, Li Y. Synthesis of 6-N, N, N- trimethyltriazole chitosan via "click chemistry" and evaluation for gene delivery. Biomacromolecules. 2009;10:2175-2182.
46. Gao Y, Xu Z, Chen S, Gu W, Chen L, Li Y. Arginine-chitosan/DNA self-assemble nanoparticles for gene delivery: in vitro characteristics and transfection efficiency. Int J Pharm. 2008;359:241-246.

\section{Publish your work in this journal}

Drug Design, Development and Therapy is an international, peerreviewed open-access journal that spans the spectrum of drug design and development through to clinical applications. Clinical outcomes, patient safety, and programs for the development and effective, safe, and sustained use of medicines are a feature of the journal, which has also been accepted for indexing on PubMed Central. The manuscript management system is completely online and includes a very quick and fair peer-review system, which is all easy to use. Visit http://www.dovepress.com/testimonials.php to read real quotes from published authors.

Submit your manuscript here: http://www.dovepress.com/drug-design-development-and-therapy-journal 